\title{
Análise de aspectos ecológicos da vegetação como ferramenta indicadora da conservação do entorno de cavernas em Laranjeiras, Sergipe
}

Analysis of the ecological aspects of the machine as indicator of conservation of the surroundings of caves in Laranjeiras, Sergipe

\author{
C. R. Donato ${ }^{1 *}$; A. S. Ribeiro ${ }^{2}$; D. G. Oliveira ${ }^{3}$; L. S. Souto ${ }^{2}$ \\ ${ }^{1}$ Colégio de Aplicação, Universidade Federal de Sergipe, 49100-000, São Cristóvão-SE, Brasil \\ ${ }^{2}$ Departamento de Ecologia, Universidade Federal de Sergipe, 49100-000, São Cristóvão-SE, Brasil \\ ${ }^{3}$ Núcleo de Ecologia e Monitoramento Ambiental, Universidade Vale do São Francisco,56302-000, Petrolina-PE, \\ Brasil \\ *christianecrd@yahoo.com.br \\ (Recebido em 29 de setembro de 2018; aceito em 30 de outubro de 2018)
}

\begin{abstract}
O presente estudo propõe a avaliação do estado de conservação do entorno de ambientes cavernícolas utilizando como critérios composição, diversidade, similaridade florística e fitossociologia em um raio de 20 $m$ a partir da entrada de cavernas. Foram analisadas nove áreas de entorno, sendo divididas em duas categorias de acordo com o estágio de sucessão secundária: inicial $(n=7)$ e tardio $(n=2)$. Foram registradas 36 espécies, das quais 21 foram classificadas como pioneiras, três como secundárias iniciais e 12 como secundárias tardias. Os fragmentos circundantes de Mata Atlântica encontram-se em sua maioria em estágio sucessional inicial, em contraposição ao estabelecido na legislação vigente. Os resultados deste trabalho poderão subsidiar a implantação de projetos de recuperação da Mata Atlântica existente na área estudada, identificando áreas prioritárias para conservação.

Palavras-chave: ambiente cárstico, bioindicador, diagnóstico ambiental.
\end{abstract}

Ecological analysis of the surrounding vegetation as an indicator tool of caves conservation status in Laranjeiras, Sergipe. This study proposes the adoption of analyzing ecological as a tool for studying the state of conservation status of adjacent areas from cave environments. We analyzed nine areas near caves, being divided into two categories, according to the secondary successional stage: early $(n=7)$ and late forest recovery $(n=2)$. We analyzed the composition, diversity, floristic and structural similarity in a radius of 20 $\mathrm{m}$ far around each cave. We surveyed 36 species, of which 21 were classified as pioneers, three as secondary and 12 as bioindicators of late successional stage. Mostly of the Atlantic forest fragments adjacent to the caves were in the early stages of secondary succession, in contrast to the Brazilian legislation. The results of this study may support the implementation of projects to restore the Atlantic Forest fragments existing in the study area, identifying priority areas of conservation.

Keywords: karst environment, bioindicator, environmental diagnosis.

\section{INTRODUÇÃO}

O estado de conservação do entorno de cavernas é crucial para determinar a sua conservação, uma vez que influencia nas características físicas e ecológicas do meio interno. A vegetação natural no entorno das cavidades possui funções ecológicas importantes relacionadas com o meio hipógeo, como forma de garantir recursos alimentares para fauna interna a partir das fezes de animais troglóxenos (como os morcegos, que usam as cavernas como abrigo, mas necessitam sair para se alimentar e até mesmo se reproduzir), ou por meio de serapilheira, galhos, folhas e raízes que são transportados pelo vento e pela água [1]. As raízes podem contribuir para reter o transporte de sedimento fino para o interior das cavernas durante chuvas fortes [2] e mesmo auxiliar na contínua formação da caverna por meio da acidificação do solo [3]. Segundo Prous et al. (2004) [4], a vegetação que envolve o entorno das cavernas, principalmente próximo às entradas, auxilia na diminuição da temperatura, luz direta, mantém a umidade e a sombra. Características essas que 
possibilitam a presença de um maior número de espécies da fauna nas entradas, com uma maior variedade de hábitats a serem colonizados.

Entende-se por caverna todo e qualquer espaço subterrâneo de origem natural e acessível ao ser humano, com ou sem abertura identificada, independentemente de seu tamanho e do tipo de rocha em que se insere, incluindo seu ambiente e características bióticas e abióticas [5]. A maioria dos trabalhos voltados para o estudo de cavernas prioriza a análise de seu ambiente hipógeo (hipogeico), com maior ênfase à zoologia, ecologia, geomorfologia e geologia (e.g. 6, 7, 8, 9).

Para identificar o estado de conservação do espaço ao redor das cavernas, um dos atributos mais importantes da comunidade é a vegetação, que caracteriza o ecossistema estudado [10]. Assim, estudos que usem a vegetação do entorno das cavernas como ferramenta de análise do estado de conservação externa são necessários.

Dessa forma, este estudo foi realizado com o objetivo de analisar o estado de conservação do entorno de cavernas do município de Laranjeiras, Sergipe, utilizando a florística, a dinâmica, a estrutura e os estágios sucessionais como indicadores com o intuito de gerar subsídios para a implantação de projetos de recuperação da Mata Atlântica no entorno de cavernas.

\section{MATERIAL E MÉTODOS}

\section{1 Área de estudo}

As áreas de estudo foram os entornos de nove cavernas situadas no Município de Laranjeiras, Estado de Sergipe (Tabela 1; Figura 1).

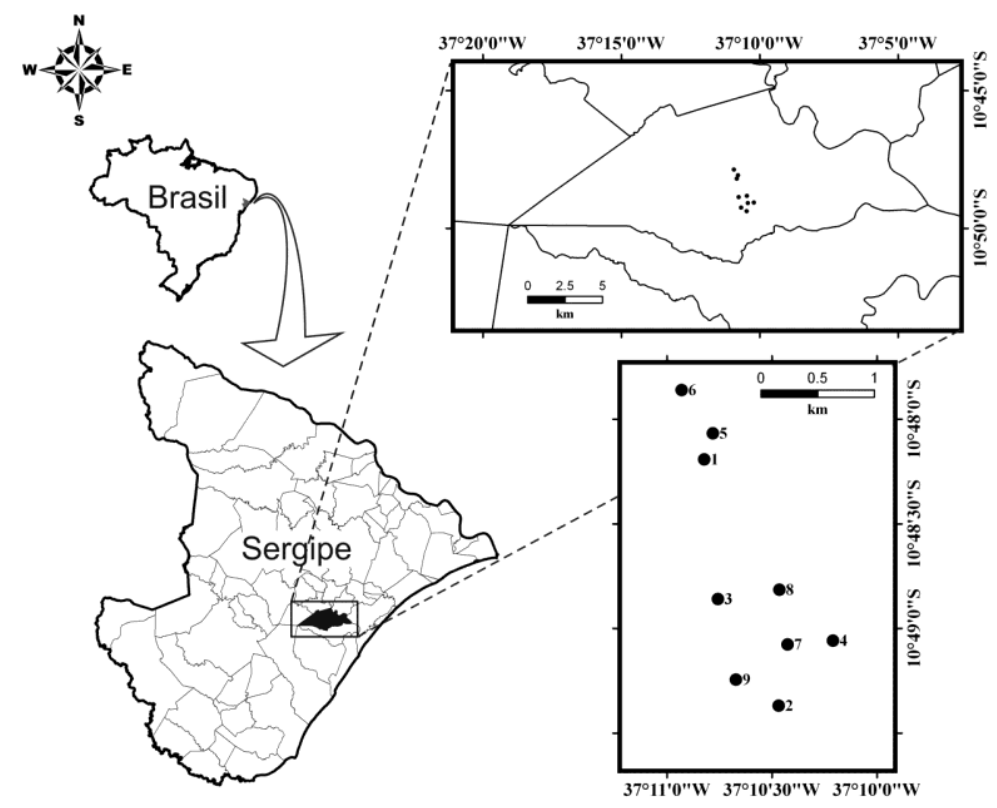

Figura 1: Mapa de localização da área de estudo com destaque no município de Laranjeiras/SE com as cavernas estudadas. 
Tabela 1: Nome das cavidades estudadas e suas respectivas localizações por localidade, coordenadas decimais e coordenadas geográficas.

\begin{tabular}{|c|c|c|c|c|}
\hline Código & Cavema & Localidade & $\begin{array}{l}\text { Coord enadas } \\
\text { Decimais }\end{array}$ & $\begin{array}{l}\text { Coordenadas } \\
\text { Geográfic as }\end{array}$ \\
\hline CAV1 & Gruta Aventureir os & Povoado $\mathrm{C}$ om andaroba & $\begin{array}{c}-10,8032 \mathrm{~S} \\
-37,1804 \mathrm{~W}\end{array}$ & $\begin{array}{l}\text { S } 10^{\circ} 48^{\prime} 115^{\prime \prime}, \\
\text { W } 37^{\circ} 10^{\prime} 49.3^{\prime},\end{array}$ \\
\hline CAV2 & Gruta da Jane la & Povoado Machado & $\begin{array}{l}-10,8228 \mathrm{~S} \\
-37,1744 \mathrm{~W}\end{array}$ & $\begin{array}{l}\text { S } 10^{\circ} 49^{\prime} 222^{\prime \prime}, \\
\text { W3 } 37^{\circ} 10^{\prime} 28^{\prime}\end{array}$ \\
\hline CAV3 & Gruta da Raposa & Povoado $\mathrm{C}$ orm andaroba & $\begin{array}{l}-10,8143 \mathrm{~S} \\
-37,1793 \mathrm{~W}\end{array}$ & $\begin{array}{l}\text { S } 10^{\circ} 48^{\prime} 516^{\prime \prime}, \\
\text { W } 37^{\circ} 10^{\prime} 45.4^{\prime \prime}\end{array}$ \\
\hline CAV4 & Gruta do Tramandá & Povoado Machado & $\begin{array}{c}-10,8176 \mathrm{~S} \\
-37,1701 \mathrm{~W}\end{array}$ & $\begin{array}{l}\text { S 10 } 10^{\circ} 49^{\prime} 035^{\prime \prime}, \\
\text { W } 37^{\circ} 10^{\prime} 12.5^{\prime}\end{array}$ \\
\hline CAVS & Gruta da Matriana & Povoado $\mathrm{C}$ om andaroba & $\begin{array}{c}-10,8011 \mathrm{~S} \\
-37,1797 \mathrm{~W}\end{array}$ & $\begin{array}{l}\text { S } 10^{\circ} 48^{\prime} 040^{\prime \prime}, \\
\text { W } 37^{\circ} 10^{\prime} 46.8^{\prime},\end{array}$ \\
\hline CAV6 & Gruta da P seudomatriana & Povoado $\mathrm{C}$ om andaroba & $\begin{array}{c}-10,7977 \mathrm{~S} \\
-37,1821 \mathrm{~W}\end{array}$ & $\begin{array}{l}\text { S } 10^{\circ} 47^{\prime} 516^{\prime \prime}, \\
\text { W } 37^{\circ} 10^{\prime} 55.7^{\prime \prime},\end{array}$ \\
\hline CAV7 & Gr uta dos Orixás & Povoado Machado & $\begin{array}{c}-10,8179 \mathrm{~S} \\
-37,1738 \mathrm{~W}\end{array}$ & $\begin{array}{l}\text { S } 10^{\circ} 49^{\prime} 046^{\prime \prime} \\
\text { W } 37^{\circ} 10^{\prime} 25.5^{\prime},\end{array}$ \\
\hline CAV8 & Gruta R aposinha & Povoado Machado & $\begin{array}{c}-10,8136 \mathrm{~S} \\
-37,1744 \mathrm{~W}\end{array}$ & $\begin{array}{l}\text { S } 10^{\circ} 48^{\prime} 489^{\prime \prime} \\
\text { W } 37^{\circ} 10^{\prime} 27.8^{\prime \prime}\end{array}$ \\
\hline CAV9 & Gruta da Pedra Furada & Povoado Machado & $\begin{array}{l}-10,8208 \mathrm{~S} \\
-37,1778 \mathrm{~W}\end{array}$ & $\begin{array}{l}\text { S } 10^{\circ} 49^{\prime} 147^{\prime \prime}, \\
\text { W } 37^{\circ} 10^{\prime} 40.2^{\prime},\end{array}$ \\
\hline
\end{tabular}

O Município de Laranjeiras está posicionado na mesorregião Leste Sergipano, microrregião Baixo Cotinguiba, na divisão climática Litoral Úmido [11]. O período de chuva concentra-se entre os meses de março a agosto e os meses mais secos vão de setembro a fevereiro. $\mathrm{O}$ índice pluviométrico médio é de $1.279,3 \mathrm{~mm}$ por ano, e a temperatura média anual é de $25,2^{\circ} \mathrm{C}$, compreendendo o clima Megatérmico Seco e Subúmido [12].

A bacia hidrográfica onde está situado o município é a do Rio Sergipe, representada localmente pelos rios Cotinguiba e Madre-Deus. Laranjeiras possui solos do tipo argissolo vermelho-amarelo, chernossolo argilúvico e halomórfico (indiscriminados de mangue) [13]. Quanto à vegetação, a maior parte do solo é coberta por áreas cultivadas e pastagem, existe manguezal próximo aos rios, com poucos espaços de Mata Atlântica [11]. O relevo é formado por colinas, cristas e interflúvios tabulares presentes na superfície dos rios Cotinguiba e Madre-Deus e planícies flúvio-marinha e fluvial na Planície Litorânea [12].

O entorno das cavernas estudadas possui vegetação secundária com remanescentes de Mata Atlântica. A vegetação secundária é importante para restauração de áreas alteradas e conservação de espécies remanescentes da vegetação primária que se encontram ilhadas por pastagens, plantações e construções urbanas [14].

\subsection{Coleta e análise de dados}

Para avaliar a vegetação associada ao entorno das cavernas, foram demarcados $20 \mathrm{~m}$ de raio a partir do centro da entrada de cada caverna, sendo $1.256 \mathrm{~m}^{2}$ de área em torno de cada uma das nove cavernas estudadas, totalizando $11.304 \mathrm{~m}^{2}$ de entorno analisado, em que se mesclavam áreas abertas e com vegetação. A análise da vegetação arbórea foi realizada com todos os indivíduos vivos com circunferência à altura do peito $(\mathrm{CAP}-1,3 \mathrm{~m}$ do solo $) \geq 5 \mathrm{~cm}$, sendo identificada a espécie e medido o seu perímetro. Os indivíduos com bifurcação abaixo do ponto de medida tiveram seus fustes medidos separadamente e o cálculo do CAP total seguiu os procedimentos conforme Scolforo \& Mello (1997) [15]. Para cada espécie foram calculados os seguintes parâmetros: área basal total (AB); densidade absoluta (DA); densidade relativa (DR); dominância absoluta (DoA); dominância relativa (DoR); e índice de valor de cobertura das espécies (VC /VC - \%).

$\mathrm{Na}$ área delimitada foi realizado o censo da vegetação, sendo todos os exemplares de cada espécie coletados e herborizados segundo procedimento estabelecido por Fidalgo \& Bononi (1984) [16]. O material botânico das espécies foi herborizado e a identificação foi feita por comparação com literatura taxonômica especializada e auxílio de especialistas do Herbário da Universidade 
Federal de Sergipe (ASE), fazendo-se o seu tombamento no acervo. As espécies foram agrupadas em famílias delimitadas de acordo com APG III [17].

A partir das coletas e observações da vegetação do entorno foi avaliado o estágio de sucessão em que se encontra a vegetação próxima às cavernas, por meio da classificação das espécies em grupos ecológicos [18], na qual as espécies foram categorizadas como pioneiras (PI), secundárias iniciais (SI) ou secundárias tardias (ST). Caracterizou-se como estágio inicial de sucessão quando $50 \%$ ou mais dos indivíduos coletados pertenceram a espécies pioneiras ou secundárias iniciais (PI e SI) e tardio quando $50 \%$ ou mais dos indivíduos coletados pertenceram a espécies secundárias tardias (ST). O estágio de regeneração da vegetação pode ser corroborado pela riqueza de espécies SI e ST, assim que quanto maior a riqueza de espécies pertencentes a esses grupos, mais avançado o estágio de regeneração [19]. Para auxiliar na avaliação do estágio sucessional e de conservação das áreas, foi observada a influência antrópica a partir da presença e ausência de espécies exóticas, as quais podem interferir no habitat tornando-o vulnerável à degradação.

Para a determinação da diversidade foi calculado o índice de Shannon-Winner (H') e para equabilidade o índice de Pielou (J). Para o cálculo destes índices foi utilizado o programa Mata Nativa 2 [20]. Para avaliar graficamente a variação na composição e abundância nas áreas foi feito um escalonamento multidimensional não-métrico (NMDS), empregando a medida de similaridade de Bray-Curtis (para dados de abundância) e 999 permutações foram geradas para a medida. Além disso, foi realizada análise de similaridade (ANOSIM) entre os dois grupos de sucessão ecológica (inicial vs. tardio) [21]. Estas análises foram feitas no programa Past [22].

\section{RESULTADOS E DISCUSSÃO}

\subsection{Composição, Diversidade, Similaridade Florística, Fitossociologia e Estágio Sucessional}

Foram amostrados 370 indivíduos, distribuídos em 36 espécies, 35 gêneros e 24 famílias no entorno das nove cavernas estudadas. As famílias mais representativas em termos de indivíduos foram Amaryladaceae (15,43\%), Rhamnaceae $(15,43 \%)$, Anacardiaceae $(14,33 \%)$ Fabaceae $(12,96 \%)$ e Rubiaceae $(4,96 \%)$, somando $63,11 \%$ do total. Em relação às espécies, as famílias mais ricas foram: Fabaceae (5), Anacardiaceae (3) e Myrtaceae (3) (Tabela 2). Ao todo 17 espécies, representadas por 38 indivíduos, foram consideradas raras nas áreas de entorno, uma vez que obtiveram menos de três exemplares amostrados.

Duas das espécies citadas na tabela 2, Zizyphus joazeiro Mart, espécie de Caatinga, e Machaerium hirtum (Vell.) Stellfeld., árvore pioneira que ocorre predominantemente na Mata Atlântica, foram encontradas no entorno de nove e sete de cavernas, respectivamente. Estas duas se destacam por serem espécies pioneiras indicadoras de habitats degradados e em regeneração.

A similaridade florística calculada entre as áreas variou de $\approx 20 \% \mathrm{a} \approx 60 \%$. O entorno da Gruta da Raposa apresentou a menor similaridade, apenas $20 \%$ em relação às demais áreas. As áreas da Gruta da Pseudomatriana e da Gruta Raposinha apresentaram a maior similaridade ( $\approx 60 \%)$ com os entornos de outras cavernas.

Quanto aos grupos ecológicos, considerando-se todas as áreas, foram identificadas 21 espécies pioneiras $(58,3 \%)$, três secundárias iniciais $(8,3 \%)$ e 12 secundárias tardias $(33,3 \%)$ (Tabela 2). A área basal total da amostragem foi $11,49 \mathrm{~m}^{2} \cdot \mathrm{ha}^{-1}$.

No levantamento foram registradas seis espécies exóticas nos entornos das cavernas: Mangifera indica L., Carica papaya L., Malpighia glabra L., Syzygium jambolanum (Lam.) DC., Bambusa vulgaris Schrad. ex J.C. Wendl. e Citrus sp. Todas elas são espécies cultivadas pelo homem, o que denota uma influência antrópica no histórico de ocupação da área das cavernas, entretanto, não se observou uma dominância destas espécies nas áreas avaliadas, o que não caracteriza um processo de invasão por plantas exóticas (Tabela 2). 


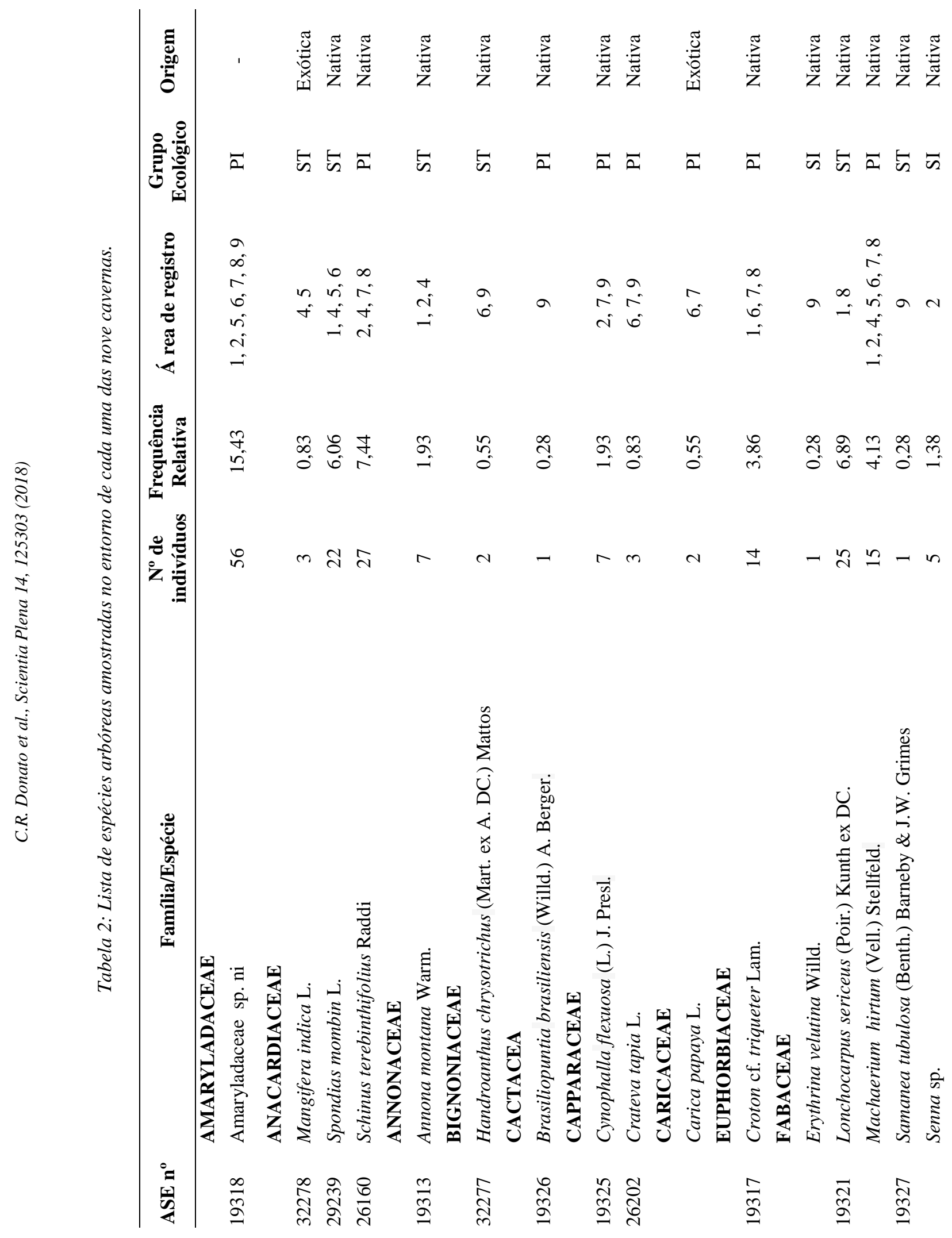




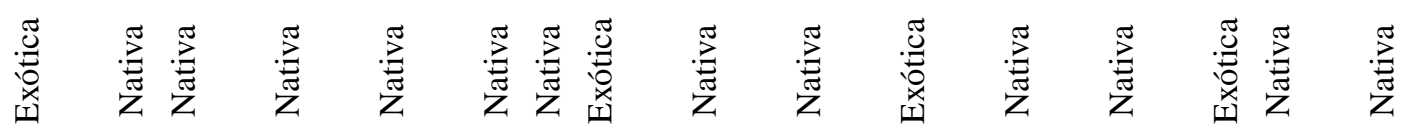

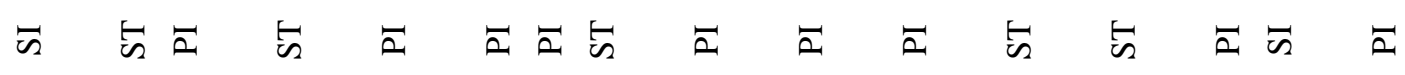

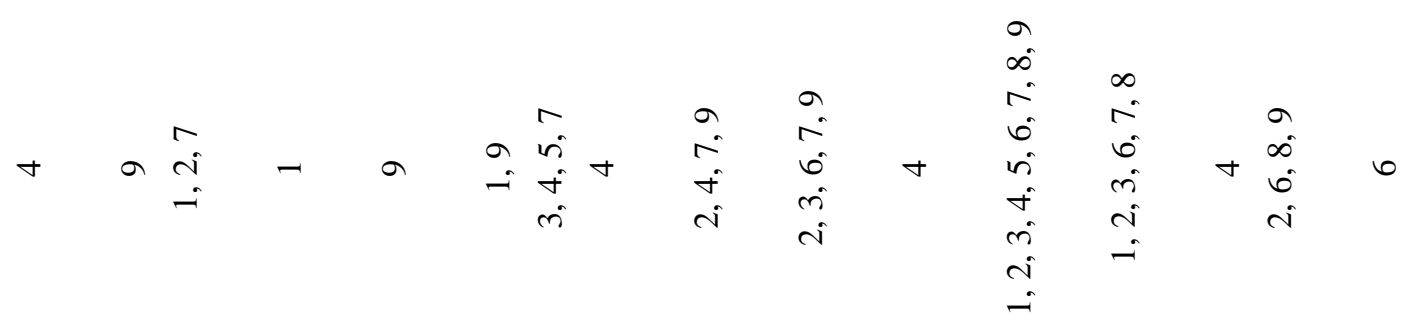

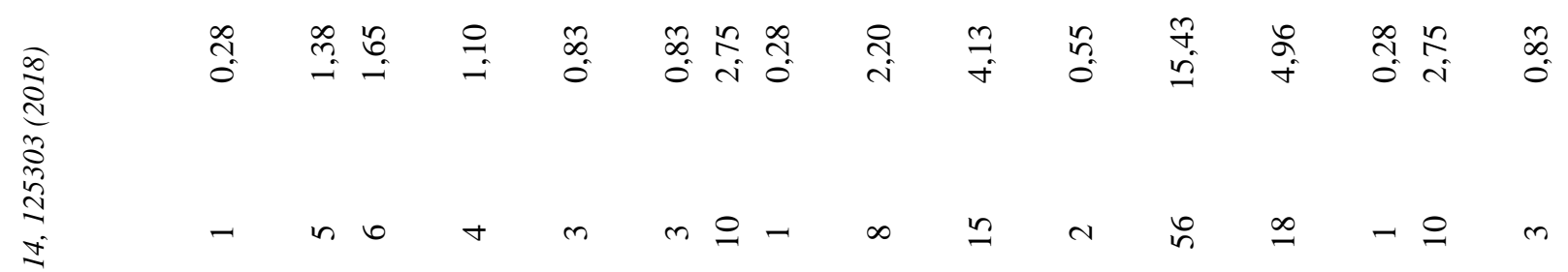

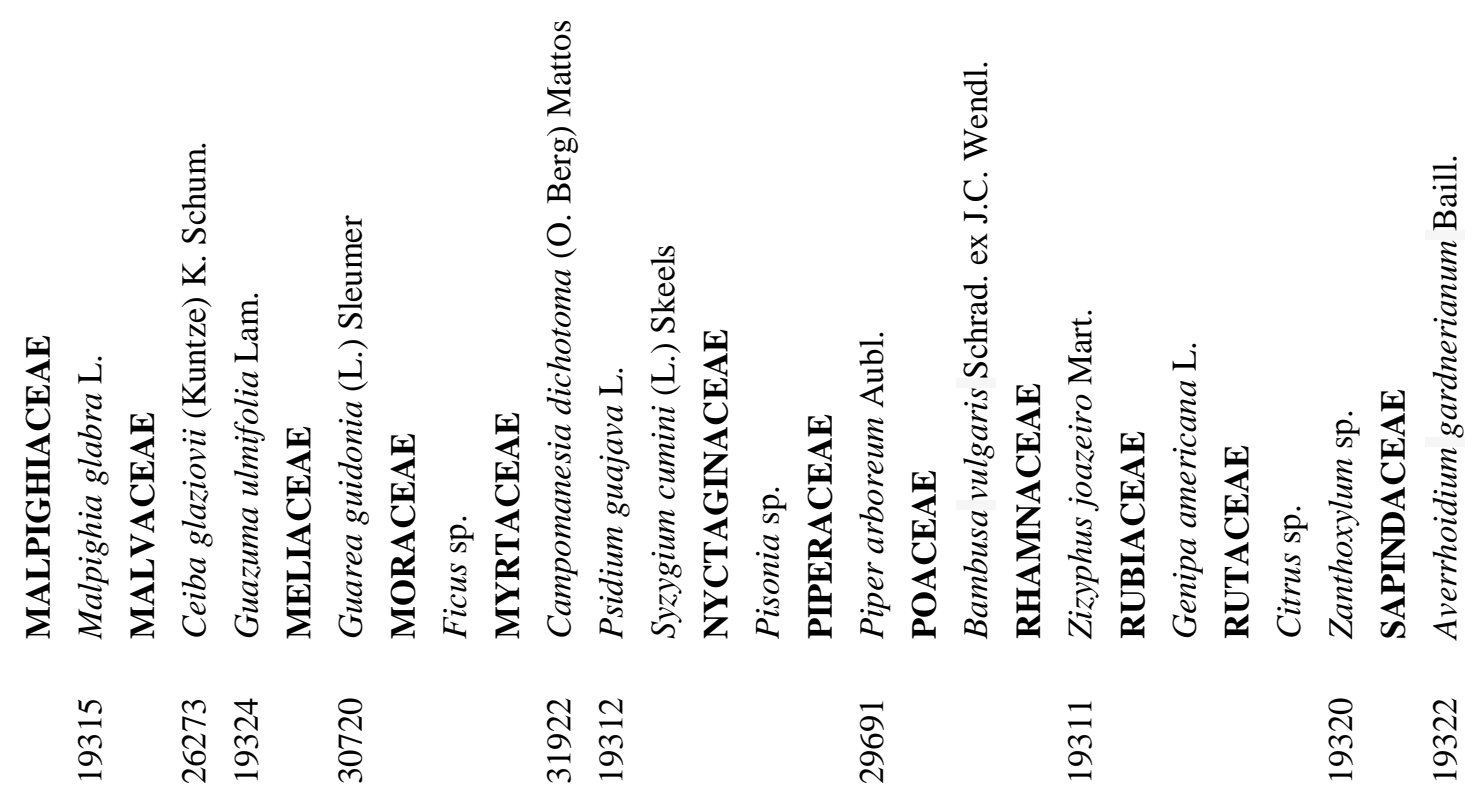




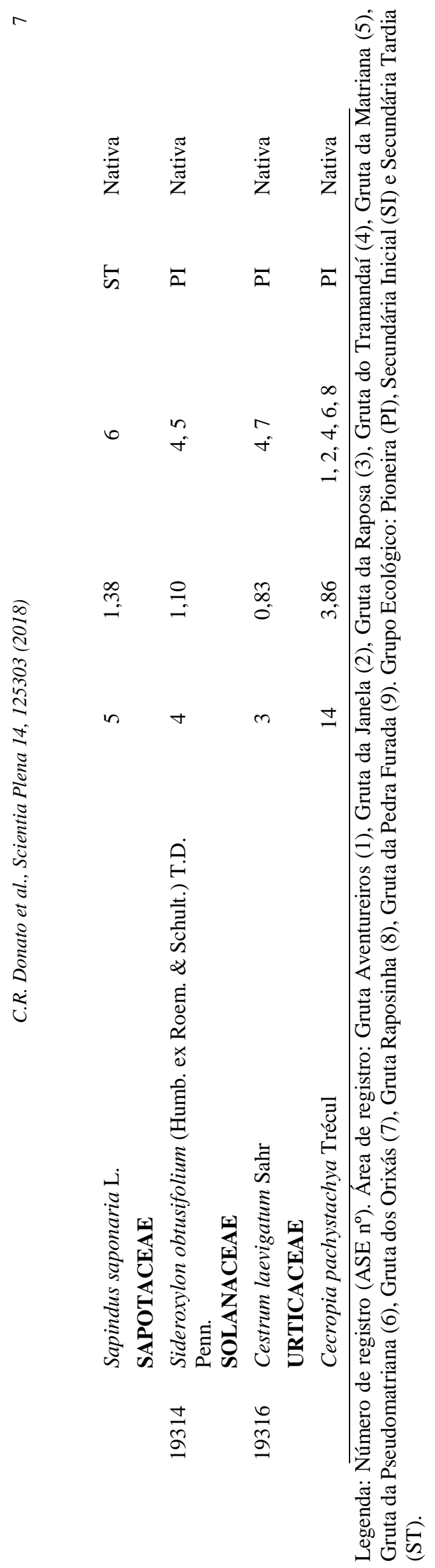


Os valores dos parâmetros quantitativos da vegetação para cada categoria variaram de acordo com a área analisada (Tabela 3). A menor riqueza de espécies ocorreu na Gruta da Raposa (4 spp.) e a maior na Gruta do Tramandaí (15). Porém, considerando a equabilidade de Pielou (J), a Gruta da Raposa apresentou o maior valor de uniformidade $(J=0,96)$ na distribuição das espécies arbóreas e arbustivas no entorno das cavernas. A importância desta avaliação de conservação está relacionada como um bom indicador de qualidade do habitat, processos sucessionais e funcionais. Melo (2008) [23] critica o uso destes índices, isto é, os índices de diversidade aplicados sobre amostras diferindo riqueza de espécies e equabilidade podem produzir o mesmo valor, ou seja, na sua visão esses índices não contribuem de fato na compreensão da diversidade local. Neste estudo, uma alta uniformidade nas proporções do número de indivíduos/espécies dentro da comunidade vegetal no entorno da caverna demonstrou que a equabilidade na área da Gruta da Raposa de fato não auxilia na observação do estado de conservação, uma vez que o valor de riqueza é baixo.

Tabela 3: Diversidade da vegetação do entorno a partir de $20 \mathrm{~m}$ de raio da entrada das cavernas

\begin{tabular}{cccccc}
\hline $\begin{array}{c}\text { Área de } \\
\text { registro }\end{array}$ & Cavernas & $\mathbf{N}$ & $\mathbf{S}$ & $\mathbf{H}^{\prime}$ & $\mathbf{J}$ \\
\hline Cav1 & Gruta Aventureiros & 52 & 12 & 1,93 & 0,78 \\
Cav2 & Gruta da Janela & 52 & 13 & 2,30 & 0,90 \\
Cav3 & Gruta da Raposa & 6 & 4 & 1,33 & 0,96 \\
Cav4 & Gruta do Tramandaí & 64 & 15 & 2,29 & 0,85 \\
Cav5 & Gruta da Matriana & 20 & 7 & 1,44 & 0,74 \\
Cav6 & Gruta da Pseudomatriana & 46 & 14 & 2,38 & 0,91 \\
Cav7 & Gruta dos Orixás & 34 & 14 & 2,36 & 0,89 \\
Cav8 & Gruta Raposinha & 29 & 9 & 1,97 & 0,90 \\
Cav9 & Gruta da Pedra Furada & 60 & 14 & 1,97 & 0,75
\end{tabular}

Legenda: Número de indivíduos $(\mathrm{N})$; riqueza de espécies arbóreas (S); índice de diversidade ShannonWeaver (H'); índice de uniformidade de Pielou (J).

Foi constatado que os nove pontos estudados estão em estágio de sucessão secundária, porém, de acordo com a caracterização desses estágios [18], foi possível distinguir duas cavernas com características de sucessão tardia e sete cavernas em estágio inicial de sucessão (Tabela 4).

Tabela 4: Estágio sucessional do entorno (20 m de raio a partir da entrada, ou seja, $\left.1.256 \mathrm{~m}^{2}\right)$ das cavernas estudadas.

\begin{tabular}{clcccc}
\hline $\begin{array}{c}\text { Área de } \\
\text { registro }\end{array}$ & \multicolumn{1}{c}{ VC\% plantas dominantes } & PI & SI & ST & ES \\
\hline Cav1 & Spondias mombin L. - 30\% & 11 & 1 & 40 & ST \\
Cav2 & Cecropia pachystachya Trécul - 14,9\% & 30 & 16 & 6 & SI \\
Cav3 & Genipa americana L. - 62\% & 2 & 0 & 4 & SI \\
Cav4 & Schinus terebinthifolius Raddi - 24\% & 37 & 1 & 26 & SI \\
Cav5 & Spondias mombin L. - 63,8\% & 7 & 0 & 13 & ST \\
Cav6 & Sapindus saponaria L. - 19,3\% & 24 & 0 & 22 & SI \\
Cav7 & Schinus terebinthifolius Raddi - 16,7\% & 25 & 0 & 9 & SI \\
Cav8 & Amaryladaceae sp. ni - 19,5\% & 21 & 3 & 5 & SI \\
Cav9 & Amaryladaceae sp. ni - 28,1\% & 39 & 2 & 19 & SI
\end{tabular}

Legenda: Área de registro: Gruta Aventureiros (Cav 1), Gruta da Janela (Cav 2), Gruta da Raposa (Cav 3), Gruta do Tramandaí (Cav 4), Gruta da Matriana (Cav 5), Gruta da Pseudomatriana (Cav 6), Gruta dos Orixás (Cav 7), Gruta Raposinha (Cav 8), Gruta da Pedra Furada (Cav 9). Grupo Ecológico: Pioneira (PI), 
Secundária Inicial (SI) e Secundária Tardia (ST). Estágio Sucessional (ES) de acordo com Gandolfi et al. (1995).

A Gruta Aventureiros possui o entorno mais conservado, com 76,9\% de sua densidade relativa pertencendo a espécies secundárias tardias, o que pode ser explicado por sua localização em Área de Preservação Permanente (APP), com um afluente do Rio Cotinguiba passando por dentro da caverna e parte do entorno ser composta por mata ciliar "strictu sensu”. Esta vegetação tem todas as características ecossistêmicas de mata ciliar, a qual altera as suas margens com deposição de sedimentos, sementes dispersas pela água [24].

A Gruta da Janela possui $57,7 \%$ de indivíduos do grupo ecológico pioneiro e $11,5 \%$ de secundário tardio. Esta cavidade está localizada em área pertencente a uma indústria mineradora (Cimento Sergipe S/A - CIMESA) e está em estágio inicial de sucessão secundária.

A Gruta da Raposa localiza-se em área particular de uso para pastagem de bovinos apresentando quatro indivíduos pertencentes ao grupo ecológico secundário tardio, todavia, isso não é o suficiente para indicar que a área está em estágio tardio de sucessão secundária, já que há domínio de espécies herbáceas e seus valores de riqueza e abundância de espécies arbóreas são baixos. Assim, considera-se esse fragmento em estágio inicial de sucessão secundária.

A Gruta do Tramandaí também está em estágio inicial de sucessão secundária com 57,8\% dos indivíduos pertencentes ao grupo ecológico pioneiro. A área é de propriedade particular, pertence à reserva legal da CIMESA e já foi utilizada como sítio e possui cinco espécies exóticas, o que corresponde a $6,3 \%$ da riqueza desse fragmento, agravando o estado de conservação desse remanescente de Mata Atlântica.

O entorno da Gruta da Matriana está em meio a uma plantação de cana-de-açúcar da Usina de Açúcar São José do Pinheiro. A maioria dos indivíduos presentes neste entorno estão no grupo ecológico secundário tardio (65\%). O fato de esses indivíduos estarem presentes principalmente sobre a rocha encaixante da caverna ou próximos a ela indica a importância dessa cavidade como prioritária a ser conservada. Cerca de 5\% dos indivíduos arbóreos do entorno são de espécies frutíferas, como a espécie exótica Mangifera indica, possivelmente propagadas pelos próprios trabalhadores rurais da usina. Assim, apesar do fragmento ser classificado em estágio tardio de sucessão secundária, existe a ameaça do avanço da monocultura canavieira e da possível dominância de espécies exóticas no futuro.

O entorno da Gruta da Pseudomatriana também se encontra em meio ao canavial da Usina de Açúcar São José do Pinheiro, com 52,2\% de sua DR sendo de espécies pioneiras e possui um indivíduo de espécie exótica cultivada (Carica papaya). Assim, considera-se que o fragmento está em estágio inicial de sucessão secundária.

A Gruta dos Orixás encontra-se também em área pertencente à CIMESA e está próxima a um campo de futebol feito para a população do Bairro Machado. Dentre os valores encontrados, 73,5\% dos indivíduos presentes nesse entorno estão no grupo ecológico pioneiro, o que indica que este fragmento está em estágio inicial de sucessão.

A Gruta Raposinha encontra-se em uma propriedade privada que possui a maioria de suas espécies arbóreas classificadas como pioneiras (72,4\%). A área sofreu desmatamento em outubro de 2010 para utilização como pastagem para bovinos. Há permanência de espécies arbóreas do grupo ecológico secundário tardio (Genipa americana e Lonchocarpus sericeus) associadas à entrada da caverna. Contudo, a presença dessas espécies não é suficiente para indicar um estágio de sucessão avançado e provavelmente sua ocorrência deve-se ao fato de serem frutíferas e poderem ser utilizadas pelos proprietários. Assim, pode-se considerar a área como de estágio inicial de sucessão secundária.

A Gruta da Pedra Furada localiza-se em propriedade privada pertencente à Fazenda Boa Luz. É o fragmento que possui maior abundância (60) e uma das maiores riquezas (14) de espécies, as quais se encontram principalmente sobre a caverna. A maioria dos indivíduos é do grupo ecológico pioneiro (65\%). Pode-se dizer que esse é um fragmento em estágio inicial de sucessão secundária, contudo é importante conservá-lo devido a espécies como a Ceiba glaziovii e Brasiliopuntia brasiliensis, endêmicas da região de Mata Atlântica (restinga).

Além da análise fitossociológica, foi possível observar, por meio do escalonamento multidimensional não-métrico (NMDS), que os fragmentos de vegetação do entorno formam uma 
sutil separação em dois grupos de sucessão ecológica (inicial e tardio) (Figura 2) . Entretanto, não houve diferença significativa entre os grupos, de acordo com a análise de similaridade (ANOSIM; $\mathrm{p}=0,078 ; \mathrm{R}=0,44$ ). Essa sutil diferenciação (basicamente os pontos 1 e 5 em relação aos demais) pode estar mais associada a fatores locais, uma vez que os pontos 1, 5 e 6 formam um grupamento de cavernas separado pelo Rio Cotinguiba e não estão no bairro Machado. Essas mudanças no contexto de paisagem poderiam tornar estas áreas estruturalmente (ou floristicamente) mais próximas, em virtude das estratégias ou limitação de dispersão dos indivíduos arbóreos, porém mesmo assim o ponto 6 apresentou ordenamento de espécies mais próximo aos pontos identificados como de sucessão inicial.

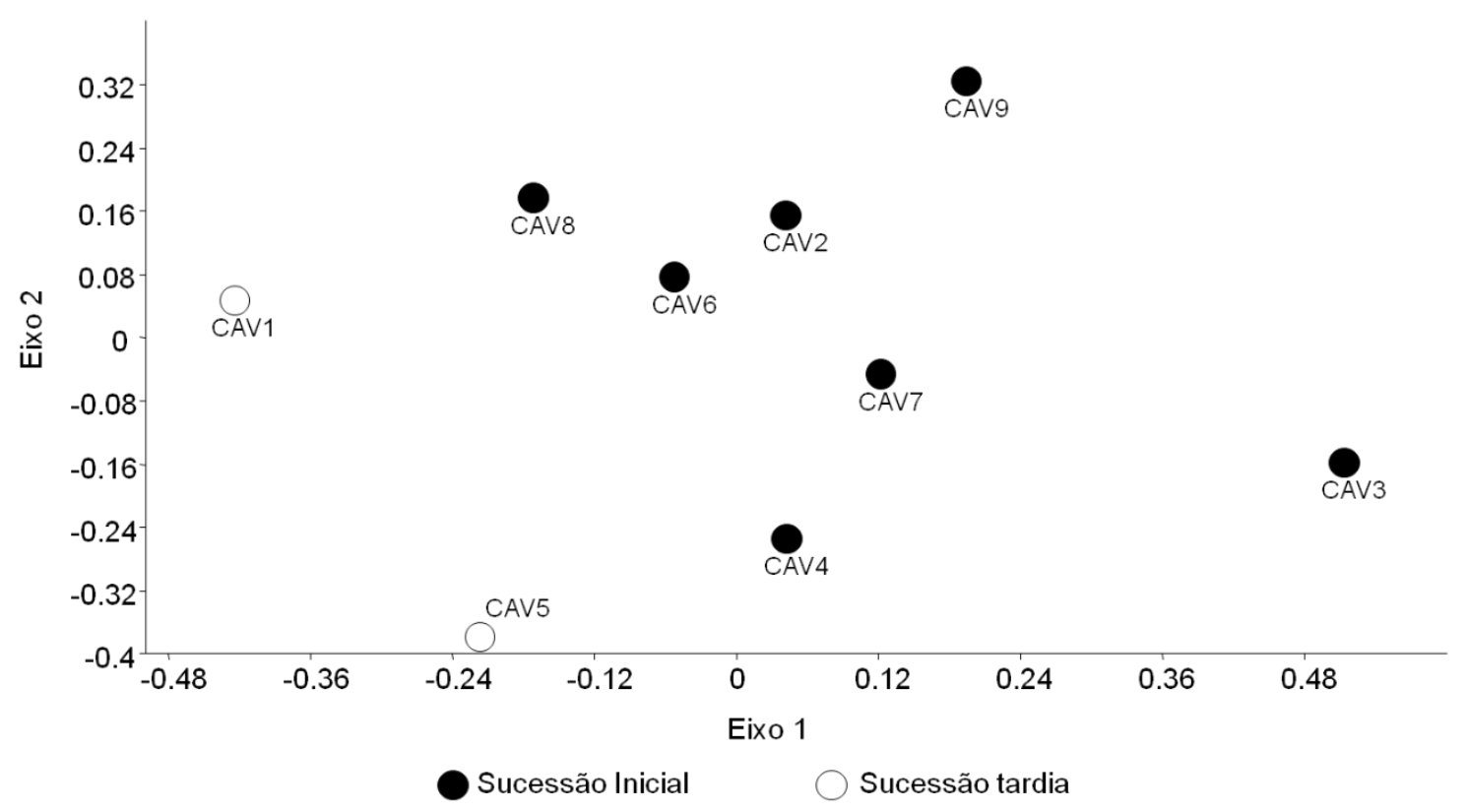

Figura 2: Ordenação (NMDS) indicando os pontos de amostragem agrupados pelo estágio de regeneração (inicial e tardia), de acordo com classificação de Gandolfi et al. (1995). Legenda: Cavernas: Gruta Aventureiros (Cav 1), Gruta da Janela (Cav 2), Gruta da Raposa (Cav 3), Gruta do Tramandaí (Cav 4), Gruta da Matriana (Cav 5), Gruta da Pseudomatriana (Cav 6), Gruta dos Orixás (Cav 7), Gruta Raposinha (Cav 8), Gruta da Pedra Furada (Cav 9).

Aspectos da vegetação do entorno podem ser um importante indicador do estado de conservação de cavernas no Brasil, auxiliando a identificação de áreas prioritárias para a conservação. $\mathrm{O}$ presente estudo identificou que a vegetação do entorno de nove cavernas do município de Laranjeiras encontra-se predominantemente no estágio inicial de sucessão, com a ocorrência de espécies vegetais exóticas de amplo uso humano (maioria frutíferas), indicando uma forte intervenção antrópica nesses entornos.

A composição florística observada apresentou dominância de algumas espécies, padrão típico para fragmentos de florestas tropicais [25, 26]. Sendo assim, essa característica nos entornos das cavernas estudadas está dentro dos padrões de fragmentos florestais tropicais. A predominância do estágio inicial de sucessão reflete o baixo valor total de área basal observado na região de estudo $\left(11,49 \mathrm{~m}^{2} \cdot \mathrm{ha}^{-1}\right)$ e indica uma baixa densidade de indivíduos arbóreos, predominantemente de espécies pioneiras. Este grupo de espécies normalmente apresenta baixa longevidade e consequentemente um menor incremento de área basal [27]. A vegetação pioneira presente em larga escala nas áreas estudadas foi derivada de ações antrópicas de derrubada da vegetação para abrir espaço para pastagens e plantações de monocultura de cana-de-açúcar.

A diversidade florística mensurada pelo índice Shannon-Weaver (H') situa-se geralmente entre 1,3 e 3,5 podendo alcançar 4,5 em ambientes florestais tropicais [28]. Com isso, pode-se considerar que todos os entornos estão dentro da faixa de variação para esse índice. Ao comparar esses índices com os dados de sucessão ecológica, pode-se observar que nem sempre o valor de diversidade 
encontrado refere-se ao ambiente em estágio de sucessão tardia e mesmo podem não ser os que possuem maior riqueza de espécies, possivelmente devido a fatores históricos inerentes a cada ponto amostrado.

Ao analisar a similaridade florística, Kent \& Coker (1992) [29] explicitam que valores maiores ou iguais a 50\% indicam alta similaridade. Nesta perspectiva, as cavernas Gruta da Pseudomatriana e Gruta Raposinha possuem alta similaridade florística, em relação a todas as demais cavernas. A Gruta da Raposa apresentou maior divergência nos índices em relação às demais, o que pode estar relacionado à baixa riqueza de espécies e abundância, considerando a área de amostragem. Apesar disso, a análise de similaridade (ANOSIM) indica que a composição florística de todos os nove entornos avaliados representa o pool regional de espécies, indicando que o distanciamento dos pontos amostrais encontrado é devido em parte ao tamanho da área amostral $\left(1.256 \mathrm{~m}^{2}\right)$, onde em alguns casos ocorreram espécies comuns em todas as áreas, porém com poucos indivíduos ou mesmo espécies representadas por um único indivíduo (raras). Além disso, fatores históricos de ocupação e uso da terra podem contribuir para as diferenças de ordenação observadas, uma vez que: (1) as cavernas Gruta Aventureiros e Gruta da Matriana estão separadas das demais pelo Rio Cotinguiba; (2) a Gruta Aventureiros está em área de proteção permanente; e (3) a Gruta da Matriana apresenta os indivíduos remanescentes de Mata Atlântica acima de sua estrutura rochosa, o que impediu que as árvores fossem derrubadas para plantio de cana-de-açúcar. Assim, essas duas cavidades tendem a apresentar maior riqueza e densidade de árvores mesmo em pequenas parcelas, porém tendo a ocorrência de espécies vegetais comuns às outras áreas.

A pesquisa dos grupos sucessionais e ecológicos aos quais as plantas pertencem auxilia para agrupar as mais semelhantes e na recuperação da vegetação original [10]. As sete cavernas com entornos classificados como de sucessão secundária inicial, conforme classificação de Galdolfi $e t$ al. (1995) [18], estão localizadas em propriedades privadas com usos diversos (agropastoril, turismo e extração mineral) próximas a áreas residenciais, o que facilita o acesso a elas. Por outro lado, as duas cavernas que apresentaram o entorno classificado como sucessão secundária tardia estão separadas das demais pelo rio Cotinguiba, além de estarem localizadas em áreas de difícil acesso. Assim, nota-se que a barreira geográfica imposta pelo rio e por sua vegetação ripária permitiu a classificação diferenciada dessas duas cavernas.

Considerando que a legislação brasileira estabelece que o entorno de cavernas tenha uma faixa adicional de proteção de, no mínimo, $250 \mathrm{~m}$ em poligonal convexa [30], apenas os entornos de duas cavernas avaliadas apresentam condições próximas às ideais, indicando que, mesmo com a legislação em vigor, a proteção do patrimônio espeleológico não vem sendo cumprida na área de estudo.

A presença de espécies secundárias tardias em algumas cavernas deve-se principalmente às mesmas serem frutíferas e não pela regeneração natural propriamente dita. Por esse motivo, tais áreas não foram classificadas como em estágio tardio. Áreas com vegetação remanescente de Mata Atlântica no entorno das cavernas, em sua maioria, estão próximas de áreas com perturbação antrópica (pasto, monoculturas, extração mineral, habitação humana), estando sujeitas à tensão excessiva de agentes externos restritivos, como desmatamento, fogo, poluição da água pelo uso de inseticidas e plantio de espécies exóticas [31]. Apesar da possibilidade de espécies exóticas tornarem as áreas vulneráveis [32], sendo consideradas uma das maiores ameaças a biodiversidade [33], as seis espécies encontradas não apresentaram dominância na área, o que descarta a ideia de invasão de plantas exóticas na região, indicando uma possível inserção para consumo humano dos habitantes da área, por serem todas frutíferas.

\section{CONCLUSÃO}

O presente estudo demonstrou que a análise de aspectos ecológicos da vegetação do entorno das cavernas pode ser usada como ferramenta de avaliação do estado de conservação das adjacências dessas cavidades, sendo identificadas duas áreas consideradas em estágio tardio de regeneração florestal e sete áreas em estado inicial de regeneração, que refletiu parte do histórico de perturbações, da frequência de visitações atuais, e da acessibilidade dessas cavidades. A presença de espécies exóticas também foi marcante em pontos de fácil acesso, próximo a aglomerados 
urbanos ou de atividades de mineração. Entretanto, a análise da composição florística (NMDS e ANOSIM) indicou que a vegetação encontrada compõe o pool regional e que não é possível distinguir os pontos com base em uma parcela de $1.256 \mathrm{~m}^{2}$.

Apesar de terem ocorrido diferenças entre os valores de diversidade e equabilidade, não houve diferença significativa de similaridade florística entre as áreas, possivelmente em virtude de todas as cavidades estarem localizadas em uma mesma região. Além disso, nos pontos com menor riqueza os valores de J, H', etc. podem variar bastante. Sendo assim, a melhor forma de diagnosticar o estado de conservação de uma caverna é por meio de um protocolo mais abrangente, porém de fácil elaboração [34].

Das cavernas estudadas, apenas a Gruta Aventureiros possui seu entorno cumprindo o estabelecido na legislação vigente como área conservada, já que está em regeneração avançada. Nos demais entornos de cavernas estudados, parte dos $250 \mathrm{~m}$ em poligonal convexa no entorno das cavernas está constituído por clareiras em que espécies nativas ou exóticas herbáceas e arbustivas são seus principais componentes vegetais.

O tipo de uso e ocupação do solo ao redor das cavernas influencia na conservação dos fragmentos florestais presentes no seu entorno, onde cavidades localizadas em uma matriz de extração mineral, sujeitas a perturbações antrópicas e uso turístico apresentam classificação diferente das localizadas em áreas de proteção permanente (APP). Há necessidade de se expandir esse estudo florístico para avaliar o estado de conservação do entorno de outras cavidades naturais subterrâneas existentes no Estado. Esse diagnóstico poderá subsidiar possíveis atividades que auxiliem na conservação desses fragmentos e das cavernas que se situam neles, como a implementação de corredores ecológicos entre fragmentos e recuperação das áreas degradadas, seja com reflorestamento utilizando vegetação nativa ou mantendo os locais sem ação humana direta, para que a vegetação nativa se restabeleça naturalmente.

\section{AGRADECIMENTOS}

Ao DAAD, pelo apoio financeiro; a Juliana Cordeiro e Vinícius Reis pelo auxílio à coleta do material florístico; à Patrício Adriano da Rocha e Mário André Trindade Dantas pela organização do mapa da figura 1; aos dois revisores anônimos, que com suas contribuições melhoraram sobremaneira a qualidade do texto e à equipe do Herbário da Universidade Federal de Sergipe (ASE) pela contribuição na identificação das espécies.

\section{REFERÊNCIAS BIBLIOGRÁFICAS}

1. Ferreira RL, Gomes FT, Silva MS. Uso da cartilha "Aventura da vida nas cavernas" como ferramenta de educação nas atividades de turismo em paisagens cársticas. Revista Científica da Seção de Espeleoturismo da Sociedade Brasileira de Espeleologia. 2008;1(2):145-164. Disponível em: http://www.cavernas.org.br/ptpc/ptpc_v1_n2_145-164.pdf. Acessado em 29.06. 2014.

2. Bárány-Kevei I. Human impact on Hungarian Karst Terrains, with special regard to sylviculture. Acta Carsologica. 2003;32(2):175-185.

3. Ferreira RL, Martins RP Cavernas em risco de “extinção”. Ciência Hoje. 2001;29(173):20-28.

4. Prous X, Ferreira RL, Martins RP. Ecotone Delimitation: Epigean hypogean transition in cave wcosystems. Austral Ecology. 2004;29:374-382.

5. Donato CR, Ribeiro AS, Sousa-Souto L. Análise ambiental e avaliação da relevância das cavernas do Município de Laranjeiras, Sergipe. Espeleo-Tema. 2012;23(s/n):59-69.

6. Weckerly FW. Cave cricket exit counts: environmental influences and duration of surveys. Journal of Cave and Karst Studies. 2012;74(1):1-6.

7. Souza-Silva M, Ferreira RL. Caracterização ecológica de algumas cavernas do Parque Nacional de Ubajara (Ceará) com considerações sobre o turismo nestas cavidades. Revista de Biologia e Ciências da Terra. 2009;9(1):59-71.

8. Piló LB. Geomorfologia Cárstica. Revista Brasileira de Geomorfologia1. 2000;(1):88-102.

9. Auler A, Brandi R, Rubiolli E. As grandes cavernas do Brasil. Grupo Bambuí de Pesquisas Espeleológicas, Belo Horizonte; 2001. 214 p. 
10. Marangon LC, Soares JJ, Feliciano ALP, Lins CF, Brandão S. Estrutura fitossociológica e classificação sucessional do componente arbóreo de um fragmento de floresta estacional semidecidual, no município de Viçosa, Minas Gerais. Cerne. 2007;13(2):208-221.

11. Correia C O (coord.). Sergipe Atlas Digital Sobre Recursos Hídricos. Versão 1.1. Aracaju: Departamento de Administração e Controle de Recursos Hídricos, Coordenadoria de Informações sobre Recursos Hídricos, 2004. 1 CD-ROM.

12. Bomfim LFC, COSTA IVG, Benvenuti SMP. Projeto Cadastro da Infra-Estrutura Hídrica do Nordeste: Estado de Sergipe. Diagnóstico do Município de Laranjeiras. CPRM, Aracaju; 2002. 13 p.

13. EMBRAPA - Empresa Brasileira de Pesquisa em Agropecuária. Sistema brasileiro de classificação de solos. 2. ed. Embrapa /Centro Nacional de Pesquisas em Solos, Rio de Janeiro; 2006. 306 p.

14. Solorzano A, Guedes-Bruni RR, Oliveira RR. Composição florística e estrutura de um trecho de floresta ombrófila densa atlântica com uso pretérito de produção de banana, no parque estadual da Pedra Branca, Rio de Janeiro, RJ. Revista Árvore [online]. 2012;36(3):451-462. Disponível em: http://dx.doi.org/10.1590/S0100-67622012000300007. Acessado em 28.12.2012.

15. Scolforo JRS, Melo JM. Inventário florestal. Lavras: UFLA/FAEPE; 1997. 344p.

16. Fidalgo O, Bononi VLR. Técnicas de coleta, preservação e herborização do material botânico. Instituto de Botânica, São Paulo; 1984. 61 p.

17. APG III. An update of the angiosperm phylogeny group classification for the orders and families of flowering plants: APG III. Botanical Journal of the Linnean Society. 2009;161(2):105-121.

18. Gandolfi S, Leitão Filho HF, Bezerra CL. Levantamento florístico e caráter sucessional das espécies arbustivo-arbóreas de uma floresta mesófila semidecídua no município de Guarulhos, SP. Revista Brasileira de Biologia. 1995;(55):753-767.

19. Tabarelli M, Mantovani W. A regeneração de uma floresta tropical montana após corte e queima (São Paulo - Brasil). Revista Brasileira de Biologia. 1999;59(2):239-250.

20. CIENTEC. Mata Nativa 2: Sistema para análise fitossociológica e elaboração de planos de manejo de florestas nativas. CIENTEC, Viçosa, MG; 2006. 295 p.

21. Clarke KR. Non-parametric multivariate analysis of changes in community structure. Austral Ecology. 1993;18(1):117-143.

22. Hammer O, Harper DAT, Ryan PD. PAST: Palaeonthological Statistics Software Package for education and data analysis. Palaeontologia Electronica. 2001;4(1):1-9.

23. Melo AS. O que ganhamos 'confundindo' riqueza de espécies e equabilidade em um índice de diversidade? Biota Neotrop. 2008;8(3):21-27

24. Rodrigues RR, Nave AG. Heterogeneidade florística das Matas Ciliares. In: Rodrigues, R.R.; Leitão Filho, H.F. (eds.). Matas Ciliares: conservação e recuperação. 2.ed. São Paulo: EDUSP/FAPESP; 2004. p.45-71.

25. Hartshorn G. Neotropical forest dynamics. Biotropica. 1980;12:23-30.

26. Parthasarathy N. Tree diversity and distribution in undisturbed and human-impacted sites of tropical wet evergreen forest in southern Western Ghats, India. Biodiversity and Conservation. 1999;8(10):1365-1381.

27. Vale VS. et al. Composição florística e estrutura do componente arbóreo em um remanescente primário de floresta estacional semidecidual em Araguari, Minas Gerais, Brasil. Hoehnea. 2009;36(3):417-429.

28. Felfili JM, Rezende RP. Comunicações Técnicas Florestais: conceitos e métodos em fitossociologia. UNB, Brasília; 2003. 68 p.

29. Kent M, Coker P. Vegetation description analyses. Behaven Press, London; 1992. 363 p.

30. Brasil. Resolução CONAMA n ${ }^{\circ} 347$, de 10 de setembro de 2004. Ministério do Meio Ambiente: Brasília. 2004. Disponível em: http://www.mma.gov.br/port/conama/legiabre.cfm?codlegi=452. Acessado em 28.01.2010.

31. Dário FR. Influência de corredor florestal entre fragmentos da Mata Atlântica utilizando-se a avifauna como indicador ecológico [dissertação]. Piracicaba: Universidade de São Paulo; 1999. 156 p.

32. Carmo FF. Importância Ambiental e Estado de Conservação dos Ecossistemas de Cangas no Quadrilátero Ferrífero e Proposta de Áreas-Alvo para a Investigação e Proteção da Biodiversidade em Minas Gerais [dissertação]. Belo Horizonte: Universidade Federal de Minas Gerais; 2010. 98p.

33. Wilcox BA, Murphy DD. Conservation strategy: the effects of fragmentation on extinction. Americam Naturalist. 1985; 125: 879-887.

34. Donato CR, Ribeiro AS, Sousa-Souto L. A conservation status index, as an auxiliary tool for the management of cave environments. International Journal of Speleology. 2014;43(3):315-322. 